\title{
Impact of Calving Ease on Functional Longevity and Herd Amortization Costs in Basque Holsteins Using Survival Analysis
}

\author{
E. López de Maturana, ${ }^{\star 1,2}$ E. Ugarte, ${ }^{*}$ and 0 . González-Recio† \\ *NEIKER, Basque Institute for Agricultural Research and Development, PO Box 46, 01080 Vitoria-Gasteiz, Spain \\ †Departamento de Producción Animal, E. T. S. I. Agrónomos - Universidad Politécnica de Madrid. Ciudad Universitaria s/n, \\ 28040 Madrid, Spain
}

\section{ABSTRACT}

The aim of this study was to analyze the impact of calving ease $(\mathrm{CE})$ on functional longevity of Basque Holsteins, using a Weibull proportional hazards model. The data considered for the analysis were 53,353 calving records from 25,810 Holstein cows distributed across 781 herds and sired by 746 bulls. The effects included in the statistical model were age at first calving, stage of lactation, interaction between year and season of calving, 305-d adjusted milk yield, CE, herd, and sire. Calving ease was considered as a time-dependent covariate and, as was the case for the rest of covariates included in the model, had a significant effect on functional longevity. Calvings needing assistance or surgery increased culling risk by $18 \%$, when compared with unassisted calvings. The effect of $\mathrm{CE}$ on length of productive life in primiparous and multiparous cows was also investigated. A second analysis was performed replacing the $\mathrm{CE}$ effect with the interaction between parity and $\mathrm{CE}$ to evaluate the effect of $\mathrm{CE}$ in primiparous and multiparous cows. An increase in calving difficulty had a greater impact on culling during first lactations than in subsequent ones. Therefore, difficult calvings, mainly at first parities, had a high impact on herd amortization costs, increasing them by $10 \%$ in relation to easy calvings. Therefore, calving difficulty should be avoided as much as possible, especially in primiparous cows, to avoid reduction of profitability.

Key words: calving ease, functional longevity, survival analysis, herd amortization

\section{INTRODUCTION}

The importance of longevity as a functional trait in the dairy industry has greatly increased in recent years because of its impact on profitability (Essl, 1998). Lon-

Received November 6, 2006.

Accepted May 4, 2007.

${ }^{1}$ Corresponding author: elmaturana@neiker.net

${ }^{2}$ Current e-mail address: lopezdematura@wisc.edu. gevity can be defined in 2 ways (Ducrocq, 1987): 1) true longevity, indicating the ability of the cow to avoid disposal, including milk production as a cause of culling; and 2) functional longevity, showing the ability of the cow to avoid involuntary culling (i.e., culling due to reasons other than milk production). In scenarios with production quotas, profitability in herds may be maintained by avoiding or minimizing involuntary culling (van Arendonk, 1988), reducing the direct costs of raising or purchasing replacement females.

Calving ease (CE), a measure of the intensity of dystocia, is economically one of the most important functional traits (Dekkers, 1994; Dematawewa and Berger, 1997), especially for first-calf heifers. High incidence of dystocia reduces profitability in herds because it increases direct (veterinary fees, calf or cow death, and extra farmer labor) and indirect costs of the herd, compromises the reproductive performance in the next reproductive cycle, and decreases milk yield (Dekkers, 1994; Dematawewa and Berger, 1997; López de Maturana et al., 2007). The problems caused by calving difficulty increase the culling rate in herds, substantially affecting longevity in Holstein cows. Beaudeau et al. (2000), in a review of the risk of culling as a consequence of main health disorders, indicated that reproductive disorders are the most frequent culling reason, followed by udder, locomotor, and peripartum health disorders (e.g., dystocia). The review concluded that longevity is negatively affected by calving performance. Different studies showed that calving difficulty affects culling of dairy and beef cows (Dematawewa and Berger, 1997; Beaudeau et al., 2000; Rogers et al., 2004; Tarrés et al., 2004). Rajala-Schultz and Gröhn (1999), in a study about the effects of the diseases on culling decisions in Finnish Ayrshire cows, concluded that dystocia increases the risk of culling significantly during the first $30 \mathrm{~d}$ after calving and also at the end of lactation. Sewalem et al. (2006) analyzed the impact of CE on longevity using records from primiparous cows. These authors concluded that first-calf heifers with difficult calvings were more prone to be culled. However, additional studies considering all parities are needed. 
Survival analysis techniques have the most appealing set of features for analyzing longevity (Ducrocq, 1987). National genetic evaluations in most countries use survival analysis to evaluate functional longevity (available at http://www-interbull.slu.se/; accessed Apr. $20,2007)$. This method can handle censoring and timedependent covariates. Furthermore, data may be nonnormally distributed, as occurs with the length of productive life, which usually presents right-skewed distributions. Considering censored data is important because their exclusion can lead to biased results. The inclusion of time-dependent covariates allows one to consider effects that change over the period of study and helps to determine the effect of such covariates at different times during the study period (Gröhn et al., 1997). The effect of calving difficulty might change along the lifetime of the cow, specifically at each calving, and this factor must be considered as time-dependent covariate when studying its influence on longevity.

The aims of this study were 1) to investigate and quantify the impact of $\mathrm{CE}$, as a time-dependent covariate, on functional longevity of Basque Holsteins by using survival analysis and 2) to analyze its effect on herd amortization costs.

\section{MATERIALS AND METHODS}

\section{Data}

Milk production, CE, and survival data provided by EFRIFE, the Federation of Holstein Associations from the Basque Country Autonomous region in Spain, were used in the analyses. Calving ease records were collected monthly by trained technicians at the same time as milk recording (Alday and Ugarte, 1997), using the following scoring criterion: 1 = unassisted; 2 = slight assistance; 3 = needed assistance; 4 = caesarean caused by calf's size; 5 = caesareans for other reasons, such as malformations and posterior or abnormal presentations of the calf. Data from categories 3 and 4 were combined into a single category because of the low percentage of data scored as $4(0.12 \%)$. Thus, 4 classes were considered in the analyses. The percentage of records in each CE category within and across parities is shown in Table 1. Calving ease information was matched with lactation records, so that all of the cows in the resulting data set had milk yield and CE information.

Longevity was defined as the number of days from first calving to culling, death, or censoring date. Data from cows still alive or with missing culling or death dates were considered as right censored. Culling due to low milk production was accounted for in the statistical model, by including 305-d adjusted milk yield as a factor, as described below, because the interest of this study was to analyze culling due to calving difficulties.
Table 1. Frequencies (in percentages) of calving ease scores within and across parities

\begin{tabular}{lccccc}
\hline & \multicolumn{5}{c}{ Calving ease score $^{1}$} \\
\cline { 2 - 6 } & 1 & 2 & 3 & 4 & 5 \\
\hline Primiparous, \% & 34.65 & 61.91 & 2.89 & 0.17 & 0.38 \\
Multiparous, \% & 35.36 & 62.89 & 1.31 & 0.07 & 0.37 \\
Overall, \% & 35.01 & 62.41 & 2.08 & 0.12 & 0.37 \\
\hline
\end{tabular}

${ }^{1} 1=$ no assistance; $2=$ slight assistance; $3=$ needed assistance; $4=$ caesareans caused by calf's size; 5 = caesareans for other reasons, such as malformations and posterior or abnormal presentations of the calf.

An editing process was carried out to determine and improve the quality of the data set. Only records from the first 12 lactations were considered. Lactation records associated with incorrect calving, drying-off, or culling dates were removed, as were records with age at first calving outside the 18- to 40-mo range or with missing sire identification. Records from sires with fewer than 4 uncensored records of productive life of their daughters were deleted as well. After edits, the final data set consisted of 53,353 data from 25,810 Holstein cows with first calving between 1995 and 2002, distributed across 781 herds and sired by 746 bulls.

\section{Statistical Models}

Two analyses, each using different Weibull proportional hazards models, were carried out. The Weibull assumption was visually tested using the life table estimates (nonparametric estimate of the survivor curve $(\mathrm{S}(\mathrm{t}))$ against the log of time. If the assumption holds, a straight line should be obtained. Figure 1 suggests that the baseline hazard function was closely approximated by a Weibull hazard function.

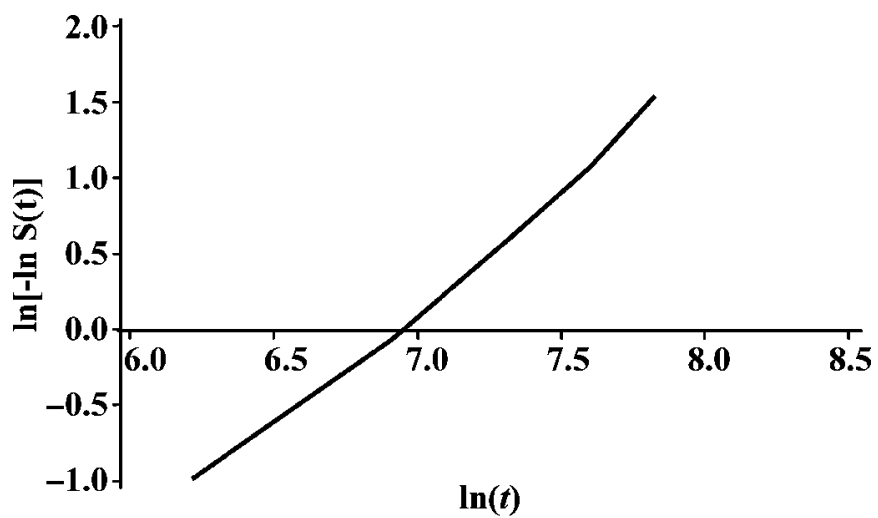

Figure 1. Graphical test of the Weibull assumption: linear regression of $\ln [-\ln S(t)]$ on $\ln (t)$. $S(t)=$ Life table estimates of the survivor function at time $t$. 
Such an approximation simplifies computations and provides baseline characteristics that can be summarized through the scale parameter $\lambda$ and the shape parameter $\rho$. Moreover, the Weibull model is quite flexible, allowing for inclusion of time-dependent covariates.

The first model included a CE effect that changed at each calving, whereas the second one included CEparity interaction changing at each calving date. Further descriptions of the models can be read below.

Model 1. The following model was used to analyze the impact of $\mathrm{CE}$ on survival:

$$
\begin{gathered}
h_{i j l m n p q}(t)=h_{0}(t) \exp \left[\mathbf{A}_{i}+\mathbf{M}_{j}(t)+\mathbf{C E}_{l}(t)\right. \\
\left.+\mathbf{L S}_{m}(t)+\mathbf{Y S}_{n}(t)+\operatorname{herd}_{p}+\operatorname{sire}_{q}\right]
\end{gathered}
$$

where $h_{i j l m n p q}(t)$ is the hazard function (instantaneous probability of culling) for an individual depending on time $\mathrm{t} ; h_{0}(t)$ is the Weibull baseline hazard function with scale parameter $\lambda$ and shape parameter $\rho ; \mathbf{A}_{i}$ is the time-independent effect of age at first calving, grouped into 3 classes: $<26,26$ to 29 , and $>29$ mo of age; $\mathbf{M}_{j}(t)$ is the time-dependent milk production effect, considering 4 classes: $<6,500 \mathrm{~kg}, 6,500$ to $7,700 \mathrm{~kg}, 7,700$ to $9,000 \mathrm{~kg}$, and $>9,000 \mathrm{~kg}$. It was assumed to be piecewise constant with change points at $t=$ calendar dates of calving; $\mathbf{C E}_{l}(t)$ is the time-dependent effect of $\mathrm{CE}(l=1$ to 4$)$, which changes at each calving date; $\mathbf{L} \mathbf{S}_{m}(t)$ is the time-dependent lactation stage ( $m=1$ to 3 ), which was assumed to be piecewise constant with change points at 0,150 and $225 \mathrm{~d}$ postpartum; $\mathbf{Y S}_{n}(t)$ is the time-dependent year-season effect ( $n=1$ to 16 ) that changes at November 1 and May 1 of each calendar year; $\operatorname{herd}_{p}$ is the random effect of herd ( $p=1$ to 781). It was assumed to follow a log-gamma distribution with parameter $\gamma$; sire $_{q}$ represents the additive genetic contribution of the sire of the cow ( $q=1$ to 2,007$)$ and was assumed to follow a multivariate normal distribution. Relationships between sires were identified through their sires and maternal grandsires.

Model 2. A second analysis was carried out, including the interaction between parity (grouped into 2 classes: primiparous and multiparous) and CE score. The hazard function was modeled as follows:

$$
\begin{gathered}
h_{i j l m n p q}(t)=h_{0}(t) \exp \left[\mathbf{A}_{i}+\mathbf{M}_{j}(t)+\mathbf{C E N P}_{l}(t)\right. \\
\left.+\mathbf{L S}_{m}(t)+\mathbf{Y S}_{n}(t)+\operatorname{herd}_{p}+\operatorname{sire}_{q}\right]
\end{gathered}
$$

where model 2 differed from model 1 only by replacing the effect of CE score with the interaction between $\mathrm{CE}$ and parity (CENP). Due to CE and parity are timedependent covariates, their interaction is another timedependent covariate, grouped into 8 classes ( $l=1$ to 8$)$.
Survival analysis was performed using the package Survival Kit v3.1 (Ducrocq and Solkner, 1994). The significance of the effects was tested by a likelihood ratio test comparing the full model with models excluding one effect at a time.

The separate estimates of the random herd effect were not considered interesting per se. Therefore, this effect was integrated out of the likelihood during the analyses (Vollema et al., 2000; Roxström et al., 2003). Estimates for the shape parameter $(\rho)$ of the baseline hazard function and for the parameter $(\gamma)$ of the loggamma distribution of herd effect were obtained. Herd variance was approximated by the trigamma function (the second derivative of the logarithm of the gamma function) evaluated at $\gamma$. The level with the lowest hazard was used as a reference and all other levels within the effect were expressed relative to that level. Risk ratios for main effects of time-dependent covariates should be interpreted with special caution because the ratio of the hazards might not be constant over time (Ducrocq, 2001).

\section{Replacement Costs According to CE}

Herd amortization is the economic term for replacement costs. It reflects annual costs for a cow to compensate its rearing costs. The following expression was used to calculate herd amortization (González Recio et al., 2004):

$$
\mathrm{HA}=\frac{1}{\frac{\mathrm{LPL}}{365}} \cdot \frac{1}{1-h m}(\mathrm{HRC})-\mathrm{SV} \cdot\left(\frac{1}{\frac{\mathrm{LPL}}{365}}-\mathrm{cm}\right)
$$

where HA is herd amortization; HRC are the costs of rearing a heifer, including replacement female calf $(\leq 6$ mo of age) value, feed, fertility, and fixed costs; SV is the salvage value, and $\mathrm{hm}$ and $\mathrm{cm}$ are heifer and cow annual mortality, respectively; LPL is the estimate of length of productive life, calculated as the median of the survivor function for each level of $\mathrm{CE}$, and was obtained from model 1 . This expression was inspired by the one used by Pérez-Cabal and Alenda (2003) for the estimation of the profit per year of productive life. For simplicity and convenience, HRC and SV were considered as invariant during the whole period of study. In addition, changes in costs of rearing heifers related to differences in ages at first calving were not considered. The herd amortization cost function had 2 parts, the revenue function, from the sale of culled cows, and the cost function, due to death of cows and those of rearing a heifer. Fixed costs were almost $48 \%$ heifer rearing costs, followed by feed costs (35\%) and replace- 
Table 2. Economic and production features of an average cow calving for the first time in year 2002 under economic circumstances of year 2004

\begin{tabular}{lc}
\hline System feature & Value \\
\hline Salvage value (€/unit) & 601 \\
Heifer rearing costs (€/unit) & \\
Replacement heifer $^{1}{ }^{0}$ 0 to 6 mo & 331 \\
Feed costs $^{1}$ & 702 \\
Fixed costs $^{1}$ & 962 \\
Fertility costs $^{2}$ & 27.38 \\
Age at first calving (d) & 846 \\
Heifer mortality (\%) & 12 \\
Cow mortality (\%) & 7 \\
\hline
\end{tabular}

${ }^{1}$ Provided by Cooperative of Services of Spanish Basque Country.

${ }^{2}$ Calculated as in González-Recio et al. (2004).

ment heifer value (16\%). Fertility costs were only $1 \%$ of the rearing costs. Revenue and cost parts depended on the LPL estimate, so that cows with longer productive life estimates had lower herd amortization costs.

Economic and production data referred to an average cow with first calving in year 2002, under the economic circumstances of year 2004, and were provided by the Cooperative of Services of Spanish Basque Country (see Table 2).

\section{RESULTS AND DISCUSSION}

Table 3 shows a summary of the data. The percentage of right-censored data was 24.45. Average failure time was $786 \mathrm{~d}$ after first calving, and the minimum and the maximum observed failure times were 14 and 2,710 d, respectively. Minimum and maximum censoring times were equal to 14 and $2,601 \mathrm{~d}$, respectively, with a mean of $717 \mathrm{~d}$.

\section{Model 1}

All of the covariates considered in model 1 had a significant effect on length of productive life. The $\rho$ esti-

Table 3. Descriptive statistics of the survival analysis of length of productive life in days (LPL)

\begin{tabular}{lr}
\hline Factors & LPL \\
\hline Total records, no. & 25,810 \\
Right censored records, no. & 6,311 \\
Minimum censoring time, d & 14 \\
Maximum censoring time, d & 2,601 \\
Average censoring time, d & 717 \\
Uncensored records, no. & 19,499 \\
Minimum failure time, d & 14 \\
Maximum failure time, d & 2,710 \\
Average failure time, d & 786 \\
Herds, no. & 781 \\
Sires in data, no. & 746 \\
Average age at first calving, d & 846 \\
Average actual milk yield, kg & 8,883 \\
Days in milk & 334 \\
\hline
\end{tabular}

Journal of Dairy Science Vol. 90 No. 9, 2007
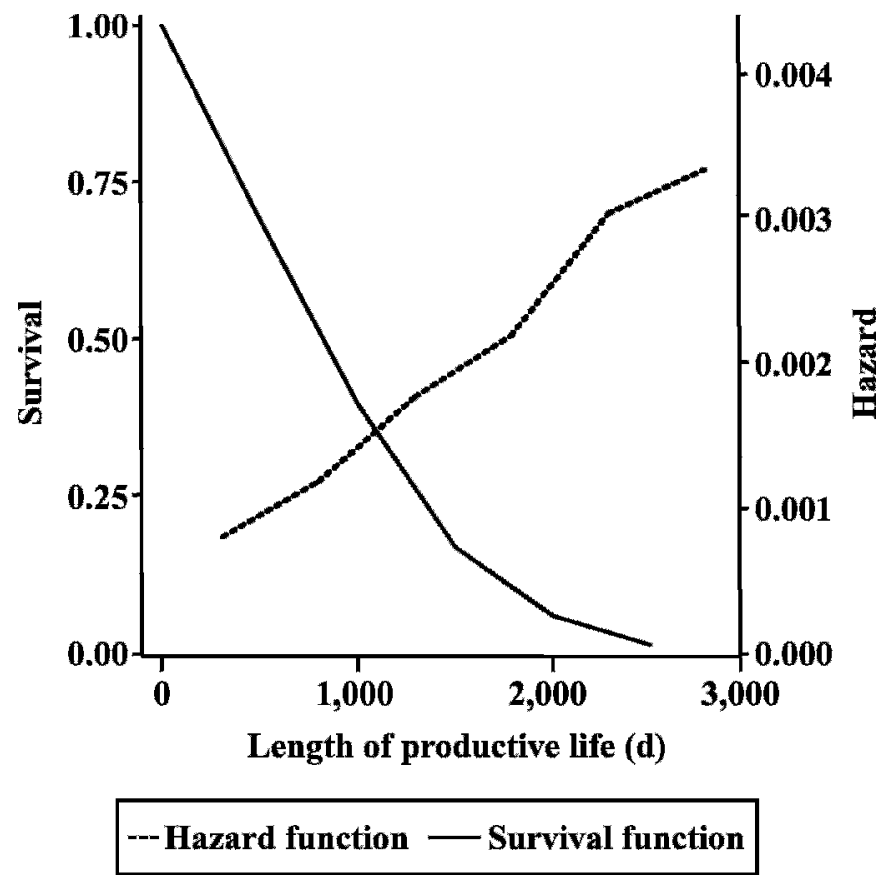

Figure 2. Baseline survival and baseline hazard functions for longevity in the Basque Holstein population.

mate was 1.65 and the intercept $\rho \log (\lambda)$ was -11.38 . Both estimates were within close range of values obtained by other authors (Ducrocq, 1994; Dürr et al., 1999; Chirinos, 2003). These 2 parameters describe the baseline survival function and the baseline hazard function for data in this study, shown in Figure 2. A $\rho$ larger than 1 indicates that the baseline hazard function increases over time. The $\gamma$ parameter estimate for the log-gamma distribution of herds was 4.16 , and its corresponding approximate variance through the trigamma function was 0.27 . The additive sire variance was estimated at 0.019 , similar to that reported by Chirinos (2003) using data from a similar population.

The lowest culling risk was found for cows calving at the youngest age $(<26 \mathrm{mo})$. Cows with age at first calving $>29$ mo had $18 \%$ greater risk than cows that had their first calving before 26 mo of age. Previous studies in dairy and beef cows also found that risk of being culled increased with delayed age at first calving (Vollema et al., 2000; Ducrocq, 2005). This fact can be related to fertility problems, as Vukasinovic et al. (2001) pointed out. In addition, high-yielding cows were less prone to be culled. Cows with the lowest production level $(<6,500 \mathrm{~kg})$ were at 0.63 times greater risk of culling than were the highest producing cows $(>9,000$ $\mathrm{kg}$ ). As expected, culling risk increased along with days in lactation. After $220 \mathrm{~d}$ postpartum, cows had around 21 times greater risk of being culled than at the begin- 
Table 4. Risk ratios (RR) associated to calving ease scores (CE)

\begin{tabular}{lllcr}
\hline Effect & Levels $^{1}$ & $\mathrm{RR}^{2}$ & $P>\mathrm{CHI}^{3}$ & $\begin{array}{c}\text { No. of } \\
\text { uncensored } \\
\text { records }\end{array}$ \\
\hline $\mathrm{CE}$ & 1 & 1.00 & $*$ & 6,881 \\
& 2 & 1.01 & 0.5665 & 12,026 \\
& 3 or 4 & 1.18 & 0.0008 & 492 \\
& 5 & 1.18 & 0.1016 & 100 \\
\hline
\end{tabular}

\footnotetext{
${ }^{1} 1=$ no assistance; 2 = slight assistance; 3 or $4=$ needed assistance, caesareans caused by calf's size; $5=$ caesareans for other reasons, such as malformations and posterior or abnormal presentations of the calf.

${ }^{2}$ Levels with lowest risk ratio within $\mathrm{CE}$ effects were set to 1 . All other levels within the effect were expressed relative to that level.

${ }^{3}$ Significance of the $\chi^{2}$ statistic, testing the difference between $R R$ associated to each $\mathrm{CE}$ score and that for $\mathrm{CE}=1$.
}

ning of the lactation. The culling is often done in the last stages of lactation, allowing the cow to stay in the herd until her lactation period ends, when it is the optimum time for replacement (van Arendonk, 1988).

Calving Ease. Calving ease scores had a highly statistically significant $(P<0.001)$ effect on functional longevity. Risk ratios associated with the 4 different $\mathrm{CE}$ classes are shown in Table 4. After adjustment for all other effects in the model, a greater CE score resulted in a greater culling risk. Cows that needed slight assistance at calving $(\mathrm{CE}$ score $=2)$ were not more prone to be culled than cows with unassisted calving $(P=0.57)$. However, the risk of being culled after needing assistance at calving or after caesareans caused by calf's size (categories 3 and 4 ) was $18 \%$ higher than the risk of being culled after unassisted calvings. Likewise, $\mathrm{CE}$ scored as 5 led to more culling risk than unassisted calvings ( $18 \%$ with a $P$-value of 0.10$)$. These results are similar to those reported in other studies (Rogers et al., 2004; Sewalem et al., 2006), although the definition of $\mathrm{CE}$ scores and the proportion of data in each category differ.

\section{Model 2}

The $\rho$ estimate was 2.14 and the intercept $\rho \log (\lambda)$ was -13.38. The $\gamma$ parameter estimate for the log-gamma distribution of herds was 3.93, and its corresponding approximate variance through the trigamma function was 0.29 . The additive sire variance was estimated at 0.026 .

The effect of the interaction between CE score and parity order was investigated. Figure 3 shows the risk ratios of primiparous and multiparous cows regarding to each CE score. First-calving cows were $17 \%$ more likely to be culled after difficult calvings $(\mathrm{CE}=3$ and 4) than after nonassisted calvings $(\mathrm{CE}=1)$. For primiparous cows, the relative culling risks after $\mathrm{CE}=2$ or

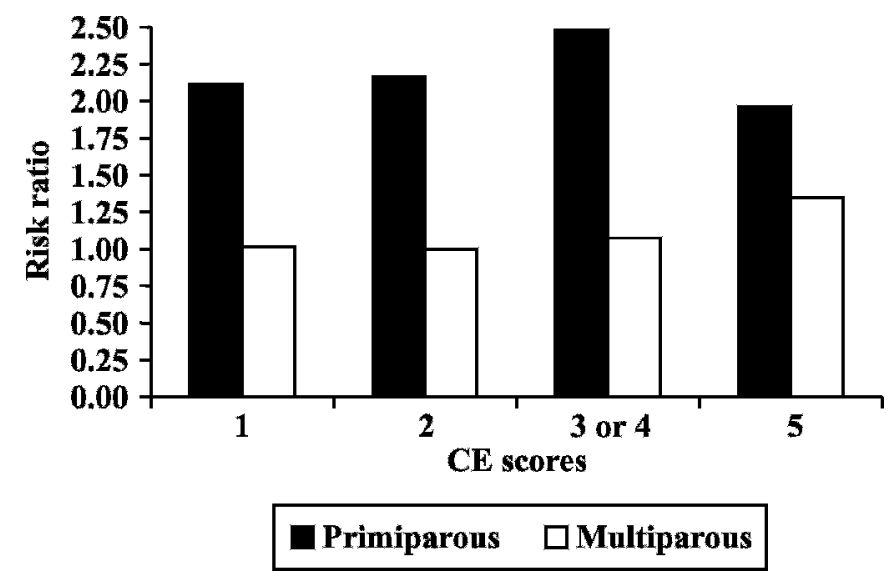

Figure 3. Risk ratio of primiparous and multiparous cows relative to calving ease scores $(\mathrm{CE})$.

$\mathrm{CE}=5$ were not significantly $(P>0.10)$ different from those after calvings needing no assistance. One must point out that the low number of uncensored records (33) for $\mathrm{CE}=5$ calvings in primiparous cows might make this result unreliable.

For multiparous cows, the greatest risk of being culled was obtained for $\mathrm{CE}=5$, with a $33 \%(P<0.01)$ greater risk of being culled than for $\mathrm{CE}=1$. However, again few uncensored records (67) were available. Unlike first-calving cows, multiparous cows with $\mathrm{CE}=3$ did not have significantly higher risk of being culled than multiparous cows with $\mathrm{CE}=1$. These results suggest that difficult calvings had a greater effect on longevity in primiparous cows.

\section{Estimated Replacement Costs According to CE}

Figure 4 shows the survivor functions for each $\mathrm{CE}$ level using the estimates from the model 1 . To construct these survivor functions, we assumed that calving performance corresponding to each $\mathrm{CE}$ score occurred repeatedly during the cow's whole life. Cows with calvings scored as 1 or 2 had similar survivor functions, as did with cows with calvings scored as 3,4 , or 5 . The rate of decrease in the observed probability of survival for each level of CE was similar until $50 \mathrm{~d}$ of productive life, in contrast to findings of Rajala-Schultz and Gröhn (1999), who indicated that the risk of culling increases significantly during the first $30 \mathrm{~d}$ after calving and then again at the end of lactation. These opposite results might be explained by the fact that different lactation stages were used in both studies. After that first period, the rate of decrease was higher for calvings scored as 3,4 , or 5 than for those scored as 1 or 2 . The difference between survival functions for calvings scored as 1 or 


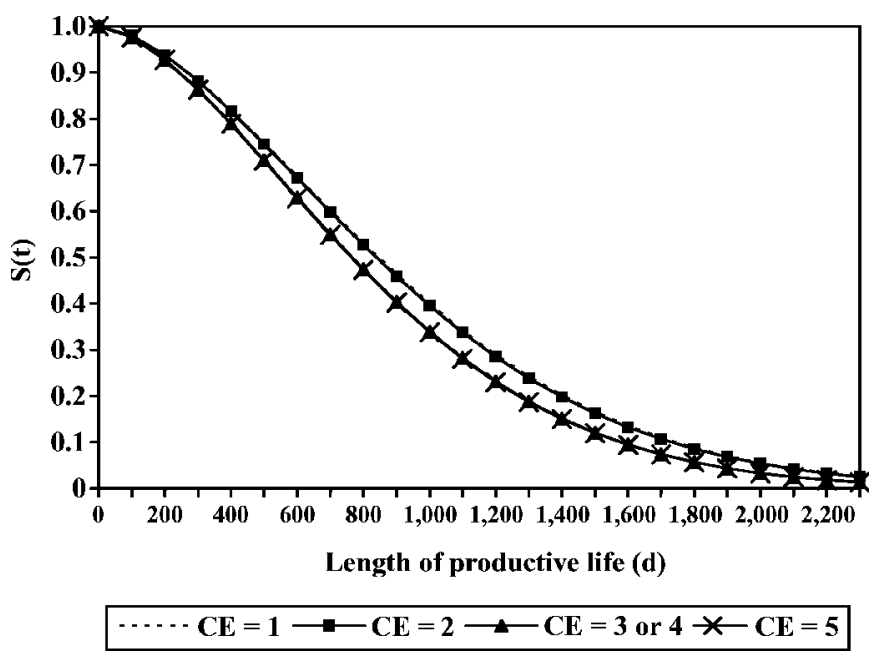

Figure 4. Survivor functions for each calving ease score (CE).

2 and those for the rest of CE scores progressively increased until the end of the productive life.

The median LPL estimates of the corresponding survivor functions, obtained with model 1 (Figure 4), were used to calculate the herd amortization costs for each CE level. The LPL estimates and their corresponding herd amortization costs are shown in Table 5. A difference of $2.5 \mathrm{mo}$ in LPL was found for cows with easy calvings $(\mathrm{CE}=1)$ in comparison with those having difficult calvings $(\mathrm{CE}=3$ or 4 ) or calvings scored as 5 . At the light of these results, a decreased in calving performance negatively affected the LPL, reducing the whole productive life by almost $10 \%$.

Calving ease had a great impact on herd amortization, as well. The herd amortization costs for a cow after a calving scored as 5 had the highest value (€875), followed by those for a cow after a calving scored as 3 or 4 (€872). The lowest values for the herd amortization

Table 5. Length of productive life (LPL) in days and herd amortization costs for calving ease levels (CE)

\begin{tabular}{|c|c|c|}
\hline Level $^{1}$ & $\mathrm{LPL}^{2} \mathrm{~d}$ & $\begin{array}{c}\text { Herd } \\
\text { amortization } \\
(€ / y r)\end{array}$ \\
\hline \multicolumn{3}{|l|}{$\mathrm{CE}$} \\
\hline 1 & 844 & 794 \\
\hline 2 & 838 & 799 \\
\hline 3 or 4 & 764 & 872 \\
\hline 5 & 762 & 875 \\
\hline
\end{tabular}

${ }^{1} 1=$ no assistance; $2=$ slight assistance; 3 or $4=$ needed assistance, caesareans caused by calf's size; $5=$ caesareans for other reasons, such as malformations and posterior or abnormal presentations of the calf.

${ }^{2}$ Calculated as the median of survivor functions of each level of CE. were obtained for easier calvings (scores 1 and 2), being $€ 794$ and $€ 799 /$ cow per yr, respectively. Thus, herd amortization costs for calvings scored as 3 or 4 , or as 5 increased by $€ 79$ to $€ 81 /$ cow per yr, when compared with calvings without any help $(\mathrm{CE}=1)$. A decrease in calving performance increased herd amortization by $10 \%$ and reduced profitability substantially.

In addition, the herd amortization costs for a primiparous cow with difficult calving ( $\mathrm{CE}=3$ or 4 ) were calculated using the LPL estimate obtained from the analysis of model 2. These costs were $€ 1,814 /$ cow per yr, which means an increase of $€ 166 /$ cow per yr when compared with those for a primiparous cow with easy calving $(\mathrm{CE}=1 ; € 1,814$ vs. $€ 1,648 /$ cow per yr). In multiparous cows, the difference between the herd amortization costs corresponding to difficult $(\mathrm{CE}=3$ or 4$)$ and easy calvings $(\mathrm{CE}=1)$ was $€ 129 /$ cow per yr less than in primiparous (assuming constant CE during the whole productive life). Those results reflect that the economical impact of culling due to calving difficulties mainly takes place after first calvings.

In conclusion, shorter productive life reduces the possibility of obtaining benefits from the subsequent lactations, increases herd amortization, and forces one to keep more heifers in the herd for replacement. This study did not take into account the increase of the needs for housing, labor, and cost due to a higher number of heifers in herd; however, its consequences should be considered at evaluating the importance of $\mathrm{CE}$ and its impact on the length of productive life.

\section{CONCLUSIONS}

Based on the results of this research, calving difficulties significantly decreased functional longevity and herd amortization costs. The effect was greater for calving difficulty in first than in later parities. Difficult calvings reduced the length of productive life by $10 \%$. Shorter productive life reduces possibility of obtaining benefits from the subsequent lactations, increases herd amortization costs by $10 \%$, and forces one to keep more heifers in the herd for replacement. This study shows that it is important to keep calving difficulties under control, especially in primiparous cows, to avoid reduction of profitability in herds.

\section{ACKNOWLEDGMENTS}

The suggestions of 2 anonymous referees contributed to improve the manuscript. The EFRIFE and Service Cooperatives of Basque Country Autonomous Region (Spain) supported this research providing field and economical data. The Department of Education of the Basque Government is gratefully thanked for financial support to E. López de Maturana. 


\section{REFERENCES}

Alday, S., and E. Ugarte. 1997. Genetic evaluation of calving ease in Spanish Holstein population. Interbull Bull. 18:21-24.

Beaudeau, F., H. Seegers, V. Ducrocq, C. Fourichon, and N. Bareille. 2000. Effect of health disorders on culling in dairy cows: A review and a critical discussion. Ann. Zootech. 49:293-311.

Chirinos, Z. R. 2003. Desarrollo de un sistema de valoración genética para la longevidad en ganado frisón español. Tesis doctoral. E.T.S.I. Agrónomos. Universidad Politécnica de Madrid, Spain.

Dekkers, J. C. M. 1994. Optimal breeding strategies for calving ease. J. Dairy Sci. 77:3441-3453.

Dematawewa, C. M. B., and P. J. Berger. 1997. Effect of dystocia on yield, fertility and cow losses and an economic evaluation of dystocia scores for Holsteins. J. Dairy Sci. 80:754-761.

Ducrocq, V. 1987. An analysis of length of productive life in dairy cattle. PhD Diss. Cornell Univ., Ithaca, NY.

Ducrocq, V. 1994. Statistical analysis of length of productive life for dairy cows of the Normande breed. J. Dairy Sci. 77:855-866.

Ducrocq, V. 2001. Survival analysis applied to animal breeding and epidemiology, course notes. University of Wisconsin-Madison.

Ducrocq, V. 2005. An improved model for the French genetic evaluation of dairy bulls on length of productive life of their daughters. Anim. Sci. 80:249-256.

Ducrocq, V., and J. Solkner. 1994. "The Survival Kit"-A Fortran package for the analysis of survival data. Proc. 5th World Congr. Genet. Appl. Livest. Prod., Guelph, Ontario, Canada.

Dürr, J. W., H. G. Monardes, and R. I. Cue. 1999. Genetic analysis of herd life in Quebec Holstein using Weibull models. J. Dairy Sci. 82:2503-2513.

Essl, A. 1998. Longevity in dairy cattle breeding: A review. Livest. Prod. Sci. 57:79-89.

González Recio, O., M. A. Pérez-Cabal, and R. Alenda. 2004. Economic value of female fertility and its relationship with profit in Spanish dairy cattle. J. Dairy Sci. 87:3053-3061.
Gröhn, Y. T., V. P. Ducrocq, and J. A. Hertl. 1997. Modeling the effect of a disease on culling: An illustration of the use of time-dependent covariates for survival analysis. J. Dairy Sci. 80:1755-1766.

López de Maturana, E., A. Legarra, L. Varona, and E. Ugarte. 2007. Analysis of fertility and dystocia in Holsteins using recursive models to handle censored and categorical data. J. Dairy Sci. 90:2012-2024.

Pérez-Cabal, M. A., and R. Alenda. 2003. Lifetime profit as an individual trait and prediction of its breeding values in Spanish Holstein cows. J. Dairy Sci. 86:4115-4122.

Rajala-Schultz, P. J., and Y. T. Gröhn. 1999. Culling of dairy cows. Part I. Effects of diseases on culling in Finnish Ayrshire cows. Prev. Vet. Med. 41:195-208.

Rogers, P. L., C. T. Gaskins, K. A. Johnson, and M. D. MacNeil. 2004 Evaluation longevity of composite beef females using survival analysis techniques. J. Dairy Sci. 82:860-866.

Roxström, A., V. P. Ducrocq, and E. Strandberg. 2003. Survival analysis of longevity in dairy cattle on a lactation basis. Genet. Sel. Evol. 35:305-318.

Sewalem, A., G. J. Kistemaker, F. Miglior, and B. J. Van Doormaal. 2006. Analysis of the relationship between fertility traits and functional longevity in Canadian Holsteins using a Weibull proportional hazards model. Proc. 8th World Congr. Genet. Appl. Livest. Prod., Belo Horizonte, Brazil.

Tarrés, J., P. Puig, V. Ducrocq, and J. Piedrafita. 2004. Factors influencing length of productive life and replacement rates in the Bruna dels Pirineus beef breed. Anim. Sci. 78:13-22.

van Arendonk, J. A. M. 1988. Management guides for insemination and replacement decisions. J. Dairy Sci. 71:1050-1057.

Vollema, A. R., S. Van Der Beek, A. G. F. Harbers, and G. De Jong. 2000. Genetic evaluation for longevity of Dutch dairy bulls. J. Dairy Sci. 83:2629-2639.

Vukasinovic, N., J. Moll, and L. Casanova. 2001. Implementation of a routine genetic evaluation for longevity based on survival analysis techniques in dairy cattle populations in Switzerland. J. Dairy Sci. 84:2073-2080. 